\title{
Epidemiology of primary tumours of the brain and spinal cord: a regional survey in southern England
}

\author{
D. J. P. BARKER, R. O. WELlER, AND J. S. GARFIELD \\ From the Departments of Community Medicine and Pathology (Neuropathology), University \\ of Southampton, and Wessex Neurological Centre, Southampton General Hospital, Southampton
}

SYNOPSIS This survey is based upon 894 patients presenting with primary tumours of the brain, spinal cord, and meninges, over a nine year period in the Wessex population of about $1 \frac{1}{2}$ million. All patients were 15 years of age or over. Each tumour type is characterized by age, sex, district, social class, and by rural or urban distribution. Standardized morbidity ratios for each tumour type are calculated for each health district. Gliomas are the commonest tumour with an average annual incidence of 3.94 per 100000 ; they occur with a lower frequency in large urban areas. Grade 3-4 astrocytomas (glioblastoma multiforme) have a peak annual incidence of 7.53 per 100000 in the 50-59 years age group and are more common in males. The peak incidence for oligodendrogliomas is also 50-59 years but for grade 1-2 astrocytomas it is 30-39 years. Meningiomas have an average annual incidence of 1.23 per 100000 with a peak incidence of 2.48 per 100000 at $60-69$ years; they have a female predominance (female 1.76 per 100000 ; male 0.64 per 100000 ). Rural districts have a lower incidence of meningiomas than urban areas. There is some variation in the distribution of gliomas, meningiomas, and Schwannomas throughout the Wessex region and there is a suggestion of geographical clustering of ependymomas, acoustic neuromas, and meningiomas. An excess of patients with grade 1-2 astrocytomas and oligodendrogliomas is seen in social classes 1 and 2 and a deficit in classes 4-5; a similar, but less marked, preponderance is seen with meningiomas.

The aetiology of primary brain tumours in the central nervous system is largely unknown. There have been few epidemiological studies of these tumours and in Britain there has been only one survey, carried out in Carlisle.

When cases can be related to the general population from which they are drawn, it becomes possible to describe the varying frequency of disease in different groups-for example, age/sex groups, geographical, and occupational groups. Such data are of importance in the study of aetiology, and also in determining the adequacy of cover of medical services.

The Wessex Neurological Centre in Southampton serves a population of approximately two million people in southern England, and the accumulation of exceptionally complete records

(Accepted 15 October 1975.) on all patients treated since the centre opened in 1965 provides the opportunity for a large retrospective study of the population.

\section{METHODS}

The Wessex Neurological Centre provides a regional neurological and neurosurgical service. In October 1974 a review was made of the records of all patients aged 15 years and over who had been treated at the centre for primary neoplasms of the brain, spinal cord, and meninges. Patients with true tumours of blood vessels or with multiple neurofibromatosis were excluded from the review as were those who were not resident within the eight health districts (Fig. 1), which correspond to the former Wessex Regional Hospital Board area (RHB). Nine hundred and thirty-six patients met the criteria for inclusion, but the records of two were unavailable at the time of the study, which therefore relates to 934 patients aged 15 years and over admitted during 1965-74. 


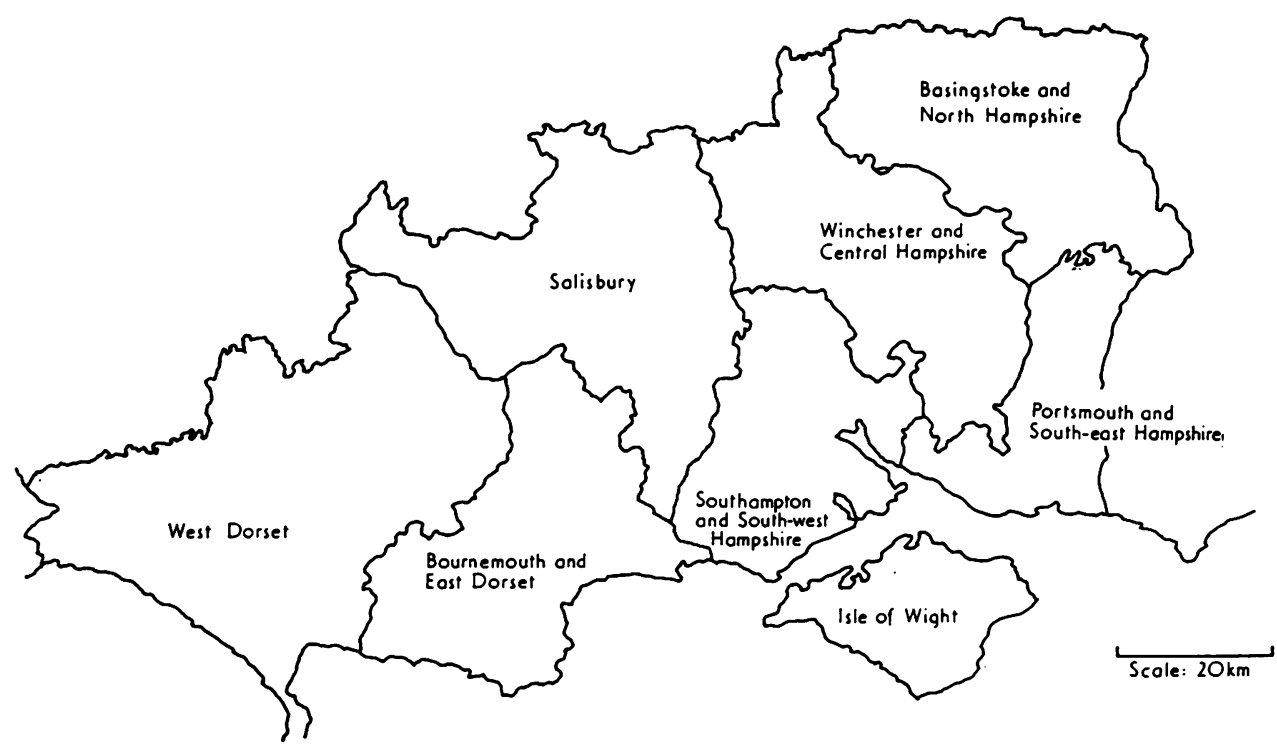

FIG. 1 Wessex health districts.

TABLE 1

BRAIN TUMOUR PATIENTS IN EIGHT HEALTH DISTRICTS

\begin{tabular}{lrrr}
\hline Health district & $\begin{array}{c}\text { No. of } \\
\text { patients }\end{array}$ & $\begin{array}{c}\text { No. in } \\
\text { population* }\end{array}$ & $\begin{array}{c}\text { Incidence } \\
\text { per 100 000 }\end{array}$ \\
\hline Bournemouth and E. Dorset & 217 & 307220 & 70.6 \\
West Dorset & 65 & 131005 & 49.6 \\
Portsmouth and S.E. Hants & 211 & 376229 & 56.1 \\
Southampton and S.W. Hants & 205 & 294659 & 69.6 \\
Winchester and Central Hants & 82 & 137543 & 59.6 \\
Basingstoke and N. Hants & 40 & 120308 & 33.2 \\
Salisbury & 57 & 91910 & 62.0 \\
Isle of Wight & 57 & 87140 & 65.4 \\
\hline Total & 934 & 1546014 & 60.4 \\
\hline
\end{tabular}

* Population figures adjusted, as described in text.

\section{RESULTS}

Table 1 shows the number of cases and the overall incidence in the eight health districts which comprise that part of the new Wessex Region corresponding to the former Wessex RHB area. The number given for the population of each district relates to people aged 15 years and over. Where the boundary of a district falls outside the former RHB area appropriate corrections have been made to the population data. A map of the eight districts is shown in Fig. 1.

The incidence of cases from the Basingstoke
TABLE 2

TYPES OF BRAIN TUMOUR

\begin{tabular}{lr}
\hline Tumour types & $\begin{array}{c}\text { No. of } \\
\text { patients }\end{array}$ \\
\hline Gliomas & 33 \\
Astrocytoma 1 and 2 & 428 \\
Astrocytoma 3 and 4 & 30 \\
Oligodendroglioma & 15 \\
Ependymoma & 102 \\
Unverified* & 158 \\
Meningioma & 61 \\
Schwannoma, neuroma, neurofibroma, & 21 \\
neurilemmoma & 4 \\
Haemangioblastoma & 3 \\
Hamartoma, vascular malformation & 3 \\
Medulloblastoma & 1 \\
Pineal tumours & 35 \\
Sarcoma of meninges & 894 \\
Unverified neoplasms* &
\end{tabular}

* See text.

district (33.2 per 100000 ) is markedly lower than in the other districts. It is known that, in the earlier years, some patients in this district were not referred to the Wessex Neurological Centre but to neurosurgical departments in London. In view of the marked under-ascertainment suggested by the low incidence figure, the Basingstoke district has been excluded from further 
TABLE 3

AGE-SPECIFIC AVERAGE ANNUAL INCIDENCE RATES PER 100000

\begin{tabular}{|c|c|c|c|c|c|c|c|}
\hline \multirow[t]{2}{*}{ Tumour type } & \multicolumn{6}{|c|}{ Annual incidence } & \multirow[t]{2}{*}{ Total } \\
\hline & $15-29$ & $30-$ & $40-$ & $50-$ & $60-$ & $70+$ & \\
\hline \multicolumn{8}{|l|}{ Gliomas } \\
\hline Astrocytomas 1 and 2 & $0.21(7)$ & $0.55(10)$ & $0.41(8)$ & $0.15(3)$ & $0.20(4)$ & $0.06(1)$ & $0.26(33)$ \\
\hline Astrocytomas 3 and 4 & $0.59(20)$ & 1.47 (27) & $3.52(69)$ & $7.53(148)$ & $6.74(133)$ & $1.82(31)$ & $3.34(428)$ \\
\hline Oligodendrogliomas & $0.15(5)$ & $0.38(7)$ & $0.15(3)$ & $0.51(10)$ & $0.20(4)$ & $0.06(1)$ & $0.23(30)$ \\
\hline Ependymomas & $0.15(5)$ & $0.27(5)$ & $0.10(2)$ & $-(0)$ & $0.15(3)$ & $-(0)$ & 0.12 (15) \\
\hline Unverified gliomas & $0.24(8)$ & $0.55(10)$ & $1.12(22)$ & $0.92(18)$ & $1.57(31)$ & $0.76(13)$ & $0.79(102)$ \\
\hline All gliomas & 1.09 (37) & $2.67(49)$ & $4.18(82)$ & $8.20(161)$ & $7.30(144)$ & $1.94(33)$ & $3.94(506)$ \\
\hline Meningiomas & $0.29(10)$ & 0.60 (11) & $1.33(26)$ & $2.44(48)$ & 2.48 (49) & $0.82(14)$ & $1.23(158)$ \\
\hline $\begin{array}{l}\text { Schwannoma, neuroma, neurofibroma, } \\
\text { neurilemmoma }\end{array}$ & $0.15(5)$ & $0.38(7)$ & $0.56(11)$ & $0.92(18)$ & $0.71(14)$ & $0.35(6)$ & $0.48(61)$ \\
\hline All tumours & $2.09(71)$ & $4.74(87)$ & $7.86(154)$ & $12.98(255)$ & $12.92(255)$ & $4.23(72)$ & $6.97(894)$ \\
\hline
\end{tabular}

Figures in parentheses are numbers of cases.

TABLE 4

AVERAGE ANNUAL INCIDENCE RATES PER 100000 BY SEX

\begin{tabular}{|c|c|c|c|c|}
\hline \multirow[t]{2}{*}{ Tumour type } & \multicolumn{2}{|c|}{ Males } & \multicolumn{2}{|c|}{ Females } \\
\hline & Incidence & No. & Incidence & No. \\
\hline \multicolumn{5}{|l|}{ Gliomas } \\
\hline Astrocytomas 1 and 2 & 0.26 & 16 & 0.25 & 17 \\
\hline Astrocytomas 3 and 4 & 4.05 & 245 & 2.70 & 183 \\
\hline Oligodendrogliomas & 0.26 & 16 & 0.21 & 14 \\
\hline Ependymomas & 0.18 & 11 & 0.06 & 4 \\
\hline Unverified gliomas & 0.91 & 55 & 0.69 & 47 \\
\hline All gliomas & 4.76 & 288 & 3.22 & 218 \\
\hline Meningiomas & 0.64 & 39 & 1.76 & 119 \\
\hline $\begin{array}{l}\text { Schwannoma, neuroma, neuro- } \\
\text { fibroma, neurilemmoma }\end{array}$ & 0.31 & 19 & 0.62 & 42 \\
\hline All tumours & 7.21 & 436 & 6.76 & 458 \\
\hline
\end{tabular}

analyses. Although significant under-ascertainment is also known to occur in the West Dorset district, from where some patients were sent to Bristol, the incidence (49.6 per 100000 ) ap-o proaches more closely to that in other districts.

TYPES OF TUMOUR Table 2 shows the types of tumour in the 894 patients. In 35 the presence of 8 a neoplasm was inferred from clinical findings and no biopsy was performed. Histology of theo tumour was obtained in 506 of the 608 patients. in whom a glioma was diagnosed. In the remaining 102 cases there was no histological verification, but as the clinicopathological correlation in the verified cases had been so high, it was decided to include the unverified group of

TABLE 5

STANDARDIZED MORBIDITY RATIOS BY HEALTH DISTRICT

\begin{tabular}{|c|c|c|c|c|c|c|c|}
\hline Tumour type & W. Dorset & Bournemouth & Salisbury & Southampton & Winchester & Portsmouth & Isle of Wight \\
\hline \multicolumn{8}{|l|}{ Gliomas } \\
\hline Astrocytomas 1 and 2 & 34 (1) & $120(8)$ & $46(1)$ & $129(9)$ & $179(6)$ & $44(4)$ & $211(4)$ \\
\hline Astrocytomas 3 and 4 & $94(38)$ & $90(88)$ & $110(30)$ & 119 (104) & $91(36)$ & 99 (106) & $91(26)$ \\
\hline Oligodendrogliomas & $36(1)$ & $143(9)$ & 51 (1) & 175 (11) & $136(4)$ & $38(3)$ & $55(1)$ \\
\hline Unverified gliomas & $42(4)$ & $107(25)$ & $31(2)$ & $87(18)$ & $138(13)$ & $117(30)$ & $149(10)$ \\
\hline All gliomas & $84(40)$ & 93 (106) & $102(33)$ & $122(126)$ & 99 (47) & $92(118)$ & $109(36)$ \\
\hline Meningiomas & 74 (11) & $135(50)$ & $100(10)$ & $98(31)$ & 70 (10) & $101(40)$ & $56(6)$ \\
\hline $\begin{array}{l}\text { Schwannoma, neuroma, } \\
\text { neurofibroma, neuri- } \\
\text { lemmoma }\end{array}$ & $70(4)$ & $144(20)$ & $258(10)$ & 121 (15) & $35(2)$ & $58(9)$ & 25 (1) \\
\hline All tumours & $77(65)$ & 107 (217) & $100(57)$ & $113(205)$ & $98(82)$ & $93(211)$ & 97 (57) \\
\hline
\end{tabular}

Figures in parentheses are numbers of cases. 


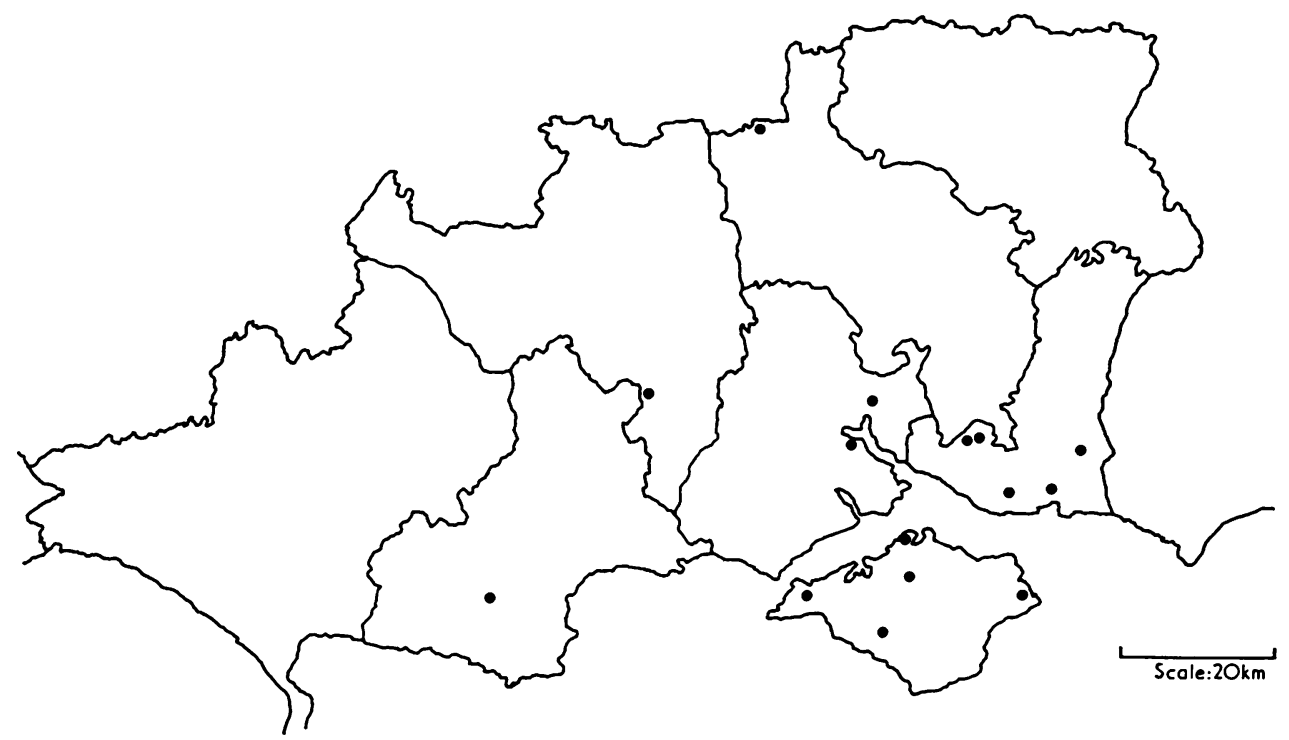

FIG. 2 Distribution of 15 cases of ependymoma.

TABLE 6

NUMBERS OF CASES OF EPENDYMOMA

\begin{tabular}{lcc}
\hline & $1965-69$ & $1970-74$ \\
\hline Isle of Wight & 4 & 1 \\
Portsmouth & 1 & 4 \\
Other districts & 2 & 3 \\
\hline
\end{tabular}

gliomas. Other than gliomas, meningiomas are the commonest tumour type.

GLIOMAS The average annual incidence of all forms of glioma combined, including those unverified by histology, is 3.94 per 100000 . The age-specific incidences increase with age until the 60-69 years age group when they decline (Table 3). Grade 3 and 4 astrocytomas (glioblastoma multiforme, see Rubinstein, 1972) the commonest form of glioma, show a similar pattern having a peak incidence of 7.53 per 100000 in the 50-59 years age group. The peak incidence for oligodendrogliomas is similarly in the 50-59 year age group, but grade 1 and 2 astrocytomas have a peak at 30-39 years. Twelve out of the 15 ependymomas occurred before the age of 50 years.
All forms of glioma have a higher incidence in males than females (Table 4). The male preponderance is greatest in grade 3 and 4 astrocytomas (4.05 per 100000 males and 2.70 per 100000 females) and in ependymomas ( 0.18 per 100000 males and 0.06 per 100000 females). In oligodendrogliomas and grade 1 and 2 astrocytomas the sex incidences are very similar.

In Table 5 incidences in the seven health districts have been compared using standardized morbidity ratios (SMR). The use of SMRs permits standardization for the different age/sex structures of the populations of the health districts. (Bournemouth, for example, has a disproportionate number of elderly people.) If the SMR of a district exceeds 100 , the incidence is higher than the average for all seven districts after allowing for the age/sex structure of the population. Likewise, an SMR below 100 indicates a below average incidence. The SMR for all forms of gliomas combined is highest in the Southampton district at 122 and lowest in West Dorset at 84 where underascertainment of brain tumours is thought to have occurred. There is little variation between the other districts. Grade 3 and 4 astrocytomas reflect this pattern with the highest SMR being in Southampton (119) but otherwise showing little variation. Grade 1 and 2 
TABLE 7

PERCENTAGE DISTRIBUTION BY SOCIAL CLASS

\begin{tabular}{|c|c|c|c|c|c|}
\hline Tumour type & $\begin{array}{c}\text { Social class } \\
1 \text { and } 2\end{array}$ & $\underset{3}{\text { Social class }}$ & $\begin{array}{c}\text { Social class } \\
4 \text { and } 5\end{array}$ & Other* & $\begin{array}{c}\text { Not } \\
\text { classified } \dagger\end{array}$ \\
\hline $\begin{array}{l}\text { Gliomas } \\
\text { Astrocytomas } 1 \text { and } 2 \\
\text { Astrocytomas } 3 \text { and } 4 \\
\text { Oligodendrogliomas } \\
\text { Ependymomas } \\
\text { Unverified gliomas } \\
\text { All gliomas } \\
\text { Meningiomas } \\
\text { Schwannoma, neuroma, neurofibroma, } \\
\text { neurilemmoma } \\
\text { All tumours }\end{array}$ & $\begin{array}{l}35(6) \\
23(54) \\
44(8) \\
38(3) \\
29(17) \\
25(71) \\
32(21) \\
26(7) \\
27(130)\end{array}$ & $\begin{array}{l}53(9) \\
54(130) \\
39(7) \\
13(1) \\
44(26) \\
52(147) \\
45(30) \\
52(14) \\
49(231)\end{array}$ & $\begin{array}{l}12(2) \\
23(55) \\
17(3) \\
50(4) \\
27(16) \\
23(64) \\
23(15) \\
22(6) \\
24(114)\end{array}$ & $\begin{array}{r}(15) \\
(175) \\
(10) \\
(5) \\
(40) \\
(205) \\
(90) \\
(34) \\
\\
(389)\end{array}$ & $\begin{array}{r}(1) \\
(14) \\
(2) \\
(2) \\
(3) \\
(19) \\
(2) \\
(0) \\
(30)\end{array}$ \\
\hline
\end{tabular}

* 'Other' includes housewives, members of the armed forces, students, retired people, and others whose occupation cannot be allocated to a social class.

$\dagger$ 'Not classified' comprises those whose occupation was inadequately recorded in the hospital notes.

Figures in parentheses are numbers of cases.

astrocytomas and oligodendrogliomas are similar in having low SMRs in West Dorset, Salisbury, and Portsmouth and high SMRs in Bournemouth, Southampton, and Winchester.

There is a suggestion of geographical clustering of cases of ependymoma. Five of the 15 patients came from the Isle of Wight and a further five from the adjacent Portsmouth district. The distribution of the cases is shown in Fig. 2. Four of the five cases on the Isle of Wight occurred in the first half of the nine year period covered by the study, while four of the five cases in the Portsmouth district occurred in the second half (Table 6).

Table 7 shows the distribution of cases by social class. Because there are no published population data on social class in the Wessex Region, a percentage distribution is shown rather than rates. The percentage distribution for the south-east and south-west of England, in which areas Wessex is included, is $21.4 \%$ in social classes 1 and $2,49.7 \%$ in social class 3 , and $28.9 \%$ in social classes 4 and 5 . Among all types of gliomas combined and grades 3 and 4 astrocytomas the distribution approximates to that of the population. But among grades 1 and 2 astrocytomas and oligodendrogliomas there is an excess of cases from social classes 1 and 2 and a deficit from social classes 4 and 5 .

In Table 8 the local authority areas are grouped into (1) large urban areas-boroughs and urban districts with populations of more than 50000 , (2) small urban areas-boroughs and urban districts with populations of less than 50000 , and (3) rural districts. For all forms of glioma combined the incidence is lowest in the larger urban areas.

MENINGIOMAS Findings for meningiomas contrast with those for gliomas. Although the incidence shows a similar increase with age, having a 8 peak of 2.48 per 100000 in the 60-69 years age? group (Table 3), there is a marked preponderanceo of female patients. Incidences are 0.64 per 100000 males and 1.76 per 100000 females. Fifty of the 158 meningiomas occurred in the Bournemouth

TABLE 8

AVERAGE ANNUAL INCIDENCE RATES PER 100000 BY LOCAL AUTHORITY AREA

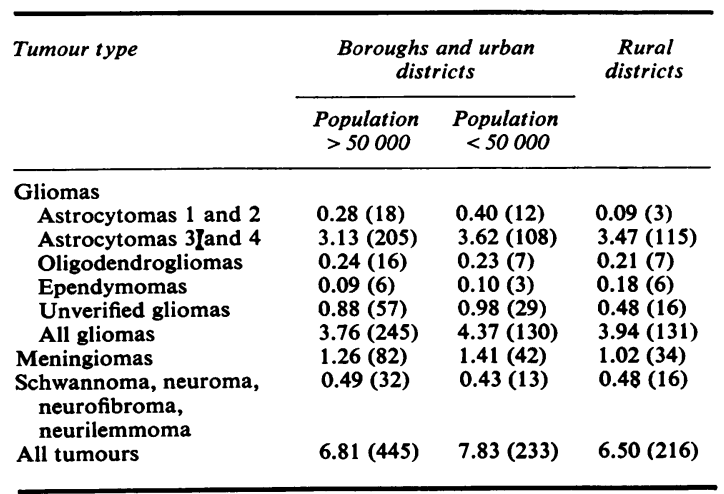

Figures in parentheses are numbers of cases. 
district, giving an SMR of $135(\mathrm{P}<0.05)$. The excess of cases in the district is not clustered within any one of the nine local authority areas comprising it. There is a slight excess of cases in social classes 1 and 2 in comparison with 4 and 5 (Table 7). The rural districts have a lower incidence of meningioma ( 1.02 per 100000$)$ than large or small urban areas (Table 8).

SCHWANNOMA, ACOUSTIC NEUROMAS, NEUROFIBROMAS, NEURILEMMOMAS Forty-four of the 61 tumours in this group are acoustic neuromas and neurofibromas. The combined incidence of these tumour types increases with age to reach a peak of 0.92 per 100000 in the 50-59 years age-group (Table 3). The incidence among females $(0.62$ per $100000)$ is double that among males $(0.31$ per 100000 ) (Table 4). There is an excess incidence in the Salisbury district (Table 5) where the SMR is $258(\mathrm{P}<0.05)$. Of the 10 cases in the district, nine were acoustic neuromas. Plotting of their addresses on the map gives no evidence of clustering of the cases in any one part of the district, and the cases were not clustered at any one time during the nine year period of this review. The percentage distribution of all tumour types by social class approximates to that expected in the population as a whole (Table 7), and the incidence was closely similar in large and small urban areas and in rural districts (Table 8).

\section{DISCUSSION}

The findings of this survey are based on ascertainment of 894 patients with primary neoplasms of the brain, spinal cord, and meninges in a population of approximately one and a half million people over a nine year period. The average annual incidence of 6.97 per 100000 for all forms of tumour is comparable with the findings of surveys in Israel (Cohen and Modan, 1968), North America (Schoenberg and Christine, 1970), and Newfoundland (Maroun and Jacob, 1973). However, in a survey in Rochester, Minnesota, the incidence of primary neoplasms of the central nervous system was found to be 15.7 per 100000 (Percy et al., 1972); but the findings in that survey, which was based on ascertainment of 174 cases over a prolonged period of 34 years, are not comparable with those in Wessex, because they include tumours ascertained for the first time at necropsy. Although some under-ascertainment of tumours in Wessex has undoubtedly occurred because of the referral of some patients in the earlier years to London hospitals, available evidence suggests that this is of small magnitude. The ratio of incidence of the two main tumour types, gliomas and meningiomas, is 3.94 to 1.23 (506 cases of glioma against 158 cases of meningioma).

In Wessex, the annual incidence of gliomas increases with age until around 60 years, whereafter it declines (Table 3). A similar age distribution of gliomas is shown by other published surveys excepting that in Rochester, where the different distribution may be attributable to necropsy ascertainment of tumours. Among the factors which may contribute to the declining incidence after 60 years of age are less precise neurological diagnosis among the elderly, whereby symptoms and signs of tumour may sometimes be attributed to cerebrovascular disease, and a greater relative frequency of symptomless as opposed to symptomatic tumours. In addition, there is often a positive decision not to investigate the elderly patient with suspected brain tumour because surgical intervention is rarely indicated: this would exclude many elderly patients from the survey, as those seen at outpatient consultations have not been included.

The higher annual incidences of gliomas among men and of meningiomas among women (Table 4) accord with findings in the published surveys already cited. Gliomas have a lower incidence in the large urban areas (populations exceeding 50000 ) than in the small urban areas or rural districts (Table 8). By contrast, meningiomas have a lower incidence in rural districts than in urban areas. No explanation of this finding is apparent.

The survey has revealed an excess of cases of grades 1 and 2 astrocytoma and of oligodendrogliomas in social classes 1 and 2. Examination of the occupations of the patients, as described in the records, does not reveal a grouping of cases in any one occupation. Although the numbers of cases are small, and therefore an uneven social class distribution may readily occur by chance, the findings will be investigated further by detailed occupational history-taking from future 
cases. There are no published findings for comparison.

In the small number of published epidemiological studies of brain tumour, evidence of geographical clustering of cases has come only from a study in Kentucky (Brooks, 1972) where there is a suggestion of clustering of gliomas in relation to rivers. In Wessex, clustering of cases at a statistically significant level was found for meningiomas in the Bournemouth district and acoustic neuromas in the Salisbury district. In addition, there was evidence of clustering of ependymomas, an uncommon tumour type, in the Portsmouth and Isle of Wight districts. It is possible that clustering of meningiomas may be related to an unevenness in the availability of specialist neurological consultations within the region, and this could also account for the higher incidence of all types of glioma combined in Southampton. However, no explanation can be suggested for the findings on acoustic neuromas and ependymomas and, to confirm them, data on future cases in Wessex will be collected, and an attempt made to obtain data from other areas of Britain.
It is a pleasure to thank Mrs Julie Curtis for her help with the extraction of data from hospital records.

Requests for reprints should be sent to Dr D. J. P. Barker, Community Medicine, South Block, General Hospital, Southampton SO9 4XY.

\section{REFERENCES}

Brooks, W. H. (1972). Geographic clustering of brain tumours in Kentucky. Cancer, 30, 923-926.

Cohen, A., and Modan, B. (1968). Some epidemiologic aspects of neoplastic diseases in Israeli immigrant population. 3. Brain tumours. Cancer, 22, 1323-1328.

Maroun, F. B., and Jacob, J. C. (1973). The frequency of intracranial neoplasms in Newfoundland. Canadian Journal of Public Health, 64, 53-57.

Percy, A. K., Elveback, L. R., Okazaki, H., Kurland, L. T. (1972). Neoplasms of the central nervous system. Epidemiologic considerations. Neurology (Minneap.), 22, 4048.

Rubinstein, L. J. (1972). Tumors of the Central Nervous System. Armed Forces Institute of Pathology: Washington D.C.

Schoenberg, B. S., and Christine, B. W. (1970). NeoplasmS of the brain and cranial meninges: a study of incidence epidemiological trends, and survival. Neurology (Minneap.) 20, 399. 